\title{
Ensuring Effective and Quality Care During a Pandemic
}

\author{
Amy Lippert, PhD
}

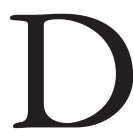

orothy Deming was a student nurse at Presbyterian Hospital in New York City when the pandemic hit. She was assigned to 12-hour duty in a "flu ward," and for 6 weeks, she "lived in the thick of the epidemic." She recalled that:

The newspapers and health authorities had given some warning but, even though our 250-bed hospital foresaw trouble, no one anticipated the suddenness of the attack. One day our student duties went on as usual: we attended classes and had supervised practice in the nursing care of patients. Then almost overnight the hospital was inundated by...victims (Deming, 1957, p. 1308).

Her story sounds as though it emerged straight from the recent headlines surrounding the coronavirus pandemic; however, the events she described took place 102 years ago.

\section{Spanish Influenza Pandemic}

Deming was recalling the Spanish influenza (flu) pandemic of 1918-1919, which killed about 675,000 people in the United States and between 20 and 50 million people worldwide-more than were killed in World War I (Flynn, 2020; Deming, 1957, p. 1308; Byerly, 2005, p. 5). George Bernard Shaw famously cribbed G. W. F. Hegel by remarking, "We learn from history that we learn nothing from history." But what if we did take the lessons of the past seriously when it comes to learning from historic pandemics?

At the end of 1918, physician George Price wrote that the influenza pandemic came to the United States in the guise of both "destroyer and teacher" (Price, 1918, pp. 367-369). Among its most important lessons, according to historian Nancy Tomes (2010, p. 49), was "the realization that those measures that worked the best to control a highly infectious disease-bans on public gatherings, school closures, and strict quarantine and isolation-were precisely the ones most difficult to implement in a modern mass society."

Failing to learn the lesson of early action and social distancing came at a steep price, then and now. The dramatically divergent death rate curves of Philadelphia and St. Louis in 1918 are illustrated in Figure 1, which was originally published in 2007 in the Proceedings of the National Academy of Sciences of the United States of America (Hatchett et al., 2007). The authors noted that the first cases of flu in Philadelphia were reported on September 17,
1918; however, they were downplayed, and officials allowed large public gatherings, notably a parade in support of the war effort on September 28th. In fact, Philadelphia did not implement social distancing measures until October $3 \mathrm{rd}$, which was when disease spread was already overwhelming medical and health resources. St. Louis authorities, by contrast, implemented measures designed to promote social distancing within 2 days of the first civilian flu cases in the city on October 5, 1918 (Hatchett et al., 2007).

This 2 -week difference in response time represented "approximately three to five doubling times for an influenza epidemic," and made Philadelphia one of the deadliest U.S. cities in which to undergo the crisis-ultimately costing 13,000 lives and surpassing the capacity of every bed in the city's 31 hospitals (Hatchett, et al., 2007, p. 7582; Flynn, 2020; Stetler, 2017, p. 462).

\section{Applying Lessons Learned From Spanish Flu to COVID-19}

In response to the rapid spread of the coronavirus disease 2019 (COVID-19), the Centers for Disease Control and Prevention (CDC) and some state and local governments are urging the same social distancing precautions now. Events such as St. Patrick's Day parades in major cities (e.g., Chicago, New York, Philadelphia), film and music festivals (e.g., South by Southwest in Austin, Coachella in California), and other large gatherings (e.g., the Houston Livestock Show and Rodeo) were canceled or postponed. The National Basketball Association and Major League Baseball also postponed their seasons (Flynn, 2020).

Many are quick to note that medical science during the Spanish flu did not benefit from the same advancements and technologies that we enjoy today. In Deming's words, "In 1918, we had no miracle drugs, no antibiotics, no oxygen or suction equipment at every bedside" (Deming, 1957, p. 1309). Of course, antibiotics are ineffective against viruses like COVID-19, and although today we have the advantage of oxygen and ventilators, they provide cold comfort when there is a nationwide-indeed, global—shortage of ventilators, let alone respiratory therapists or intensive care unit nurses capable of properly maintaining them.

In a surprising departure from the medical supply and hospital bed shortages confronting today's healthcare workers, Dr. Isaac Stern (who was a third-year University of Pennsylvania 
medical student in 1918) recalled some remarks of Dr. William Krusen (director of the Department of Health and Charities in Philadelphia):

If you would ask me the three things Philadelphia most needs to conquer the epidemic, I would tell you 'Nurses, nurses, nurses, and more nurses.' Doctors we have enough of. Supplies are plentiful, buildings are offered us everywhere... But without enough nurses to tend those we already have, we are helpless (Stetler, 2017, p. 470).

On March 11, 2020, the World Health Organization declared COVID-19 a global pandemic. Two days later, the president of the United States declared a national emergency using powers granted by the National Emergencies Act.

As Maslin Nir (2020) recently reported for The New York Times, nurses are on the frontlines of the global battle against the COVID-19 pandemic (paras. 10-11). Standing in the "hot zone" (a potentially infectious area where tests are performed) at New York's first drive-through coronavirus testing center in New Rochelle, nurse Lisa Baez-Alessandro from Staten Island acknowledged, "We have to be careful, one mistake could be a big problem." Wearing a full-body hazmat suit with yellow tape around her wrists and ankles to seal off any gaps, Baez-Alessandro nonetheless argued that "this is why we became nurses. This is the time to help. If we don't do this, what are we doing?"

\section{State Actions to Increase Nursing Care}

To facilitate the vital role that nurses and other healthcare workers play-especially in this time of crisis-regulators must act in concert with state and federal authorities to ensure the most efficient and effective means possible of moving healthcare providers into the places where they are needed - thereby fulfilling the critical mandate to ensure public health, safety, and welfare.

The Nurse Licensure Compact (NLC) is an essential resource for states during this public health crisis. For participating states, the ability for registered nurses (RNs) and licensed practical nurses/licensed vocational nurses (LPN/LVNs) who hold a multistate license to work in multiple states either in-person or via telehealth remains the same, regardless of whether that state has declared a state of emergency. In addition, the compact ensures that every nurse working in the state on the compact license has been thoroughly vetted by their board of nursing and has met 11 uniform requirements for licensure. This provides a level of security for healthcare facilities during a difficult time.

In February and March, several non-compact states passed emergency legislation, authorizing out-of-state medical personnel (among other personnel) to assist with efforts to combat and treat COVID-19. Some granted this permission through a temporary license, valid for 90 days or some other specified period. Other states enabled nurses and nursing assistants licensed in another state or U.S. jurisdiction to provide care under special provisions,
FIGURE 1

\section{Excess Pneumonia and Influenza Mortality Over 1913-1917 Baseline in Philadelphia and St. Louis, September 8 - December 28, 1918}

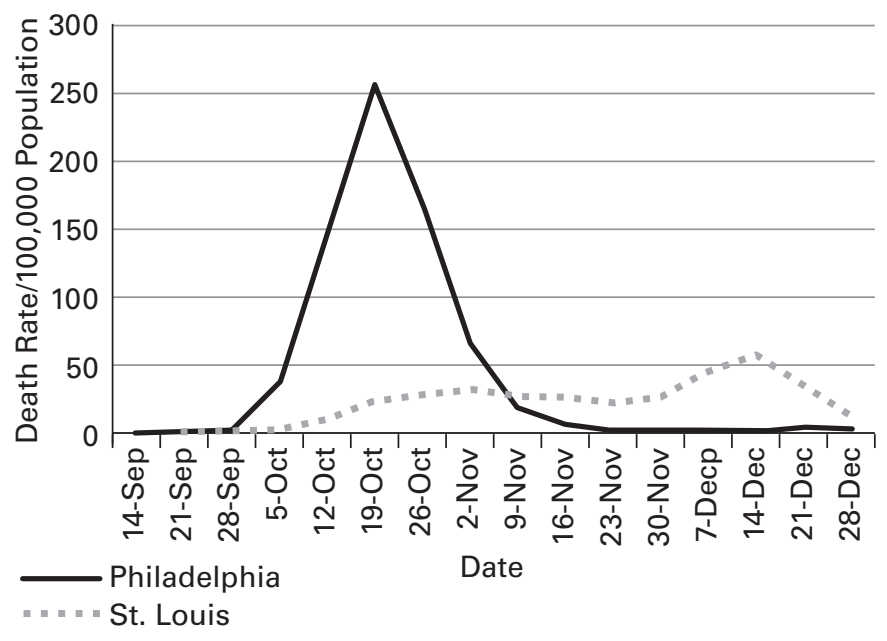

Source: Hatchett, R. J., Mecher, C. E., \& Lipsitch, M. (2007). Public health interventions and epidemic intensity during the 1918 influenza pandemic. Proceedings of the National Academy of Sciences of the United States of America, 104(18), 7582-7587. Copyright (2007) National Academy of Sciences, U.S.A. Reprinted with permission.

usually upon completion of (or proof of) training deemed adequate by the Department of Health or Commissioner of Health. Their struggles to efficiently recruit badly needed, but also qualified, nursing personnel are reminiscent of nursing shortages that Deming described 102 years ago. "The shortage of nurses, already acute because of the demands of war...was intensified by illness among the staff - 90 of our graduate nurses and students came down with flu, one died. We were also short of aides" (Deming, 1957, p. 1308).

In response to COVID-19, several jurisdictions enabled volunteers to practice without obtaining a license in the state in question, provided they were registered in the volunteer health practitioner system and verified to be in good standing in all states where they were licensed. Jurisdictions asked for retired health care professionals and individuals currently enrolled in public health, nursing, or medical school to complete a survey to determine volunteer eligibility. In other cases, non-nursing staff, upon completion of required training, were authorized to perform tasks otherwise limited to the scope of practice of a licensed or registered nurse - though these individuals were to remain under the supervision of a nurse. Others issued a temporary registration to an applicant as a certified nurse aide, regardless of whether the applicant demonstrated that he or she had successfully completed the examination requirements. The temporary registration would be valid for 28 days and could be renewed by the relevant state authority until the termination of the state of emergency. In some 
U.S. territories, hiring, overtime, and procurement were authorized by executive order, as was the suspension of any regulations that prevent, hinder, or delay the response to a public health emergency.

Some boards of nursing in non-NLC states updated their policies to expedite the processing of reciprocal license applications for nurses that were licensed in another jurisdiction. These updated policies would allow those applications to be processed as efficiently as possible - in at least one jurisdiction, within 1 business day. Other states, such as California, Massahusetts, and Michigan, reserved the ability to renew a license regardless of the number of continued education hours completed or to recognize hours worked in response to COVID-19 as hours toward continued education (e.g., Newsom, 2020; Commonwealth of Massachusetts, 2020; Whitmer, 2020).

As of April 1, ten states have temporarily waived APRN practice agreements, either in part or entirely (Indiana, Maine, Massachusetts, Michigan, Mississippi, Missouri, Pennsylvania, South Carolina, Tennessee, and Texas). Five states-Kentucky, Louisiana, New Jersey, New York, and Wisconsin-have temporarily suspended practice agreement requirements during the emergency period (AANP, 2020)..

Compact states took additional measures to provide for public protection. Public health proclamations or other forms of emergency state legislation suspended state restrictions that practitioners cannot practice with an inactive or lapsed license, though this provision was usually extended only to practitioners whose licenses had lapsed within a certain time frame, such as the past 5 years. These exceptions were also usually limited to the treatment of those affected by the public health disaster and lasted solely throughout the duration of the proclamation or state of emergency. In addition to interstate reciprocity and authorizing inactive practitioners, some NLC jurisdictions expanded the scope of practice for health care practitioners and issued temporary permits for LPNs, RNs, and advanced practice RNs who had active, unencumbered licenses in any other U.S. jurisdiction and who were entering into the state in question to respond to the declared emergency.

\section{Summary}

As Cowell recently wrote for The New York Times:

There are times when the planet resets its course with a cruelty that seems as capricious as it is implacable. The coronavirus pandemic, spreading octopus tentacles into every crevice of society, is one of them, pitting the vanity of human assumptions against nature's almost casual ability to destroy them. It is not the first time. (Cowell, 2020, p. A10)

In what has so often been characterized with military metaphors as a world war against a microscopic foe, nurses are among our bravest and most vital warriors. It behooves us all to support them with every means at our disposal and to bring the lessons of history to bear in that noble fight.

\section{References}

American Association of Nurse Practitioners. (2020, March 31). COVID19 state emergency response: Temporarily suspended and waived practice agreement requirements. https://www.aanp.org/advocacy/ state/covid-19-state-emergency-response-temporarily-suspendedand-waived-practice-agreement-requirements

Byerly, C. R. (2005). Fever of war: The influenza epidemic in the U.S. Army during World War I. New York University Press.

Commonwealth of Massachusetts Board of Registration in Nursing. (2020). Licensure Policy 10-03: Expedited processing of reciprocal license applications in the event of a declared public health emergency. https://www.mass.gov/doc/expedited-processing-ofreciprocal-license-applications-in-the-event-of-a-declared-public/ download

Cowell, A. (2020, March 22). Chronicling contagions' brutal efficiency in a century of photos. The New York Times, A10.

Deming, D. (1957). Influenza-1918: Reliving the great epidemic. The American Journal of Nursing, 57(10), 1308-1309.

Flynn, M. (2020, March 12). What happens if parades aren't canceled during pandemics? Philadelphia found out in 1918, with disastrous results. The Washington Post. https://www.washingtonpost.com/ nation/2020/03/12/pandemic-parade-flu-coronavirus/

Hatchett, R. J., Mecher, C. E., \& Lipsitch, M. (2007). Public health interventions and epidemic intensity during the 1918 influenza pandemic. Proceedings of the National Academy of Sciences of the United States of America, 104(18), 7582-7587.

Maslin Nir, S. (2020, March 17). In virus hot spot, lining up and anxious at drive-in test center. The New York Times. https://nyti. ms/2WIXUPW

Newsom, G. (2020, March 4). Executive Department, State of California: Proclamation of a state of emergency. https://www.gov.ca.gov/ wp-content/uploads/2020/03/3.4.20-Coronavirus-SOEProclamation.pdf

Price, G. M. (1918). Influenza—-destroyer and teacher: a general confession by the public health authorities of a continent. The Survey, 41, 367-369.

Stetler, C. M. (2017). The 1918 Spanish Influenza: Three months of horror in Philadelphia. Pennsylvania History: A Journal of MidAtlantic Studies, 84(4), 462-487.

Tomes, N. (2010). "Destroyer and teacher": Managing the masses during the 1918-1919 influenza pandemic. Public Health Reports, 125(Suppl. 3), 48-62.

Whitmer, G. (2020, March 17). State of Michigan, Executive Order 2020-13. Nos. 4-5. https://www.michigan.gov/whit mer/0,9309,7-387-90499_90705-522016--,00.html

Amy Lippert, PhD, is an Associate, Nursing Regulation, National Council of State Boards of Nursing, Chicago, Illinois. 